\title{
When do people derogate or psychologically distance themselves from victims? Belief in a just world and ingroup identification
}

\author{
Isabel Correia $^{\mathrm{a}, *}$, Hélder Alves ${ }^{\mathrm{a}}$, Robbie Sutton ${ }^{\mathrm{b}}$, Miguel Ramos ${ }^{\mathrm{a}}$, Maria Gouveia-Pereira ${ }^{\mathrm{c}}$, Jorge Vala ${ }^{\mathrm{d}}$ \\ a Instituto Universitário de Lisboa (ISCTE-IUL), Centro de Investigação e Intervenção Social (CIS-IUL), Av. das Forças Armadas, 1649-026 Lisbon, Portugal \\ ${ }^{\mathrm{b}}$ School of Psychology, Keynes College, University of Kent, Canterbury, Kent CT2 7NP, UK \\ ' ISPA-Instituto Universitário, Rua Jardim do Tabaco, 34, 1149-041 Lisbon, Portugal \\ d Instituto de Ciências Sociais, Av. Professor Aníbal de Bettencourt, 9, 1600-189 Lisbon, Portugal
}

\section{A R T I C L E I N F O}

\section{Article history:}

Received 21 March 2012

Received in revised form 18 May 2012

Accepted 25 May 2012

Available online $\mathrm{xxxx}$

\section{Keywords:}

Belief in a just world

Victim derogation

Social identification

Social identity

Psychological distancing

\begin{abstract}
A B S T R A C T
Two factors increase the threat for individuals' belief in a just world (BJW) posed by an innocent victim: the degree of the observer's explicit endorsement of BJW and the fact that the victim shares a common identity with the observer. In this paper, we aim to investigate whether or not these two factors (BJW and ingroup identification) have an interaction effect on each of two mechanisms that reduce the threat to BJW: victim derogation and psychological distancing from the victims. In two studies with university students we predicted and found that BJW interacted with identification with an ingroup victim to predict victim derogation (Study 1 ) and disidentification from the group shared with the victim (Study 2). In Study 1 , the positive relationship between BJW and derogation was significant for strongly identified participants but not for weakly identified participants. In Study 2, high BJW was associated with low ingroup identification only when group salience was activated.
\end{abstract}

(c) 2012 Elsevier Ltd. All rights reserved.

\section{Introduction}

Imagine that a work colleague from your department with whom you share a lot in common is run over near your office because the driver did not stop at the red traffic lights. Objectively it was the driver's fault and so it is reasonable to expect that the driver, not your colleague, is derogated. Nevertheless, this situation is likely to threaten your belief in a just world (BJW; Lerner, 1980). As counterintuitive as it may sound, you reduce this threat and restore your BJW by derogating your colleague or/and to psychologically distance yourself from him/her. To date, research has identified two factors that increase the threat that an innocent victim represents to the observers' BJW: the degree of their explicit endorsement of the BJW and the fact that the victim shares a common identity with them. In this paper, we aim to investigate whether these two factors (degree of BJW and degree of identification with the group shared with the victim) have a joint effect on two mechanisms to reduce a threat to the BJW: victim derogation and psychological distancing from the victims.

* Corresponding author. Tel.: +351 217903214; fax: +35121796 4710

E-mail addresses: isabel.correia@iscte.pt (I. Correia), havga@yahoo.com (H. Alves), R.Sutton@kent.ac.uk (R. Sutton), miguelruiramos@googlemail.com (M. Ramos).

\subsection{Threat to BJW, observers' explicit endorsement of BJW and responses to victims}

According to just world theory (Lerner, 1980) individuals need to perceive the world as a place where people get what they deserve, so that they can live with confidence and believe that no unjust events will happen to them. However, the fact that there are innocent victims contradicts this fundamental assumption about the world and, in this sense, it threatens people's BJW. In trying to deal with this threat observers of innocent victims may derogate (Lerner, 1980) or psychologically distance themselves from these victims (Hafer, 2000b) so that they can keep their BJW intact (Hafer \& Bègue, 2005, for a review). Therefore, both victim derogation and psychological distancing from a victim serve the common end of weakening the link between the self and a threatening entity (the victim) as the evidence we present next shows.

Hafer (2000b, Studies 1 and 2) found that observers psychologically distanced themselves more from an individual who posed a strong versus weak threat to their need to believe in a just world. However, that psychological distancing was not higher for high believers in a just world compared to low believers in a just world.

A great number of studies have measured participants' explicit endorsement of BJW and then compared reactions of participants scoring higher and lower in this construct (Hafer \& Bègue, 2005, for a review). The results very often show that the higher their explicit endorsement of the BJW, the higher the level of victim dero- 
gation (e.g. Correia \& Vala, 2003). This pattern has been interpreted as reflecting the fact that for these individuals an innocent victim poses a high threat to their BJW.

\subsection{Threat to BJW, victim's categorization and responses to victims}

Besides the effect showing that an innocent victim threatens individuals who have a high BJW, research has also found that sharing a common identity with the victim is a potential cause of threat to one's BJW. In fact, earlier research showed that victims of suffering perceived as similar (vs. dissimilar) to the observers were more likely avoided, especially if observers were not able to help them (Novak \& Lerner, 1968). Nevertheless in this research similarity was framed at an interpersonal level, not at an intergroup level. Later on, Lerner and Miller (1978) hypothesized that ingroup victims are more threatening to the observers' BJW than outgroup victims because the former are more relevant than the latter in indicating what may happen to observers.

Correia, Vala, and Aguiar (2007, Study 2) and Aguiar, Vala, Correia, and Pereira (2008) offered the first systematic empirical investigation to the hypothesis that an ingroup innocent victim was more threatening to the BJW than an outgroup victim. Results of both studies using a modified Stroop task (Hafer, 2000a) showed that participants who watched the ingroup victim situation (but not those who watched the outgroup victim situation) took more time to identify the color of stimuli preceded by justice-related words than by justice-neutral words.

As far as psychological distancing from a victim is concerned, Drout and Gaertner (1994) found that when asked to rate their personal similarity with a female target, females considered themselves less similar to a female victim than a female non victim. No such difference occurred among male participants. Drout and Gaertner (1994) interpreted the psychological distancing from the victim as resulting from female participants' need to reduce the threat to their BJW posed by the ingroup victim.

As far as victim derogation is concerned, Aguiar et al. (2008, Study 2) found that an ingroup victim compared with an ingroup non-victim was more derogated on an implicit measure of derogation but not on an explicit one. Although the reason(s) for this null effect are not conclusive, a likely explanation may be that participants differed in their levels of ingroup identification which was neither measured nor experimentally manipulated.

\subsection{Social identification and threat to BJW}

Research has manipulated categorization of the victim as an ingroup versus an outgroup member resting on the assumption that the former increases threat. Research has also measured psychological distance from a victim as a dependent variable. Nevertheless, we think it is important to theoretically distinguish the degree to which defining oneself as a group member may both affect and be affected by a threat to the BJW. Tajfel (1978) defined social identity as "that part of an individual's self-concept which derives from his [or her] knowledge of his [or her] membership of a social group (or groups) together with the value and emotional significance attached to that membership" (p. 63). When people categorize themselves as members of a social group this grants them a social identity and individuals define themselves in terms of social rather than personal characteristics. People belong to a variety of groups, but not all of them are important at a given time. Self-categorization theory (Turner, Hogg, Oakes, Reicher, \& Wetherell, 1987) conceptualizes social identification as a readiness to categorize the self as a member of a particular group in a certain context. This categorization accentuates intragroup similarities and intergroup differences and consequently individuals of the same category are depersonalized and perceived as more interchangeable representatives of that group.

Extending this reasoning to reactions towards innocent victims, we propose that being identified with an innocent victim's group is likely to increase the threat this victim presents to the perceived invulnerability of the self. The idea is that when an ingroup member experiences an unjust event, high identifiers will find it more probable that the same can happen to them. This argument is supported by research showing that strongly identified individuals are likely to share perceptions of common fate with other ingroup members (Jackson, 2002). On the other hand, we also propose that a lower identification with a group shared with the victim may result from a threat to BJW and not merely a decreased perception of similarity with the victim conceived in interpersonal terms.

\section{The present studies}

Previous empirical evidence suggests that under conditions of higher threat to the BJW deriving from either strong BJW or the fact that the victim shares the same categorization with the observer people may psychologically distance themselves or derogate the victim. However, research has failed to find evidence of an interaction between high BJW and shared categorization with the victim (Drout \& Gaertner, 1994). In this paper we propose to test the interaction of observers' explicit endorsement of the BJW and their group identification on victim derogation (Study 1) and psychological distancing from a victim (Study 2) who shares a common identity with the observer.

If we take into account that the higher the observers' BJW, the higher their motivation to derogate innocent victims in order to restore their perception of a just world, we can predict that for high believers in a just world there will be a positive association between ingroup identification and derogation or psychological distancing from an ingroup victim. Specifically, among participants with high belief in a just world, we expect that those who are strongly identified will derogate an ingroup victim more than those who are less identified. We also predict that participants who are more identified will psychologically distance themselves more from an ingroup victim than those who are less identified. For low believers in a just world, identification should make less difference to victim derogation or psychological distancing because their motivation to restore the perception of justice is also lower. Thus, even strongly identified individuals will not derogate the ingroup victim.

In sum, we intend to consider not only the fact that the victim and the participant share the same group (ingroup victim) but also the impact of the degree of social identification with that shared categorization between the observer and the victim on victim derogation (Study 1 ). We also intend to theoretically conceptualize the response of psychological distancing from a victim not only as perceived similarity, as in previous studies, but also as the degree of social identification with the common group between the victim and the participants (Study 2 ).

Importantly, we do not hypothesize a main effect of ingroup identification. Although social identity theory (Tajfel \& Turner, 1979) assumes that people are intrinsically motivated to perceive one's social self in a positive light, which produces ingroup favoritism, ingroup bias is not the only mechanism to achieve a positive social identity. Thus, the motivation for a positive social identity does not always produce ingroup bias (Turner, 1999).

\section{Study 1}

In this study we aim to test if there is an interaction between the observers' explicit endorsement of the BJW and their group identification on victim derogation. 


\subsection{Methods}

\subsubsection{Participants}

Seventy-two university students participated in this study. The sample comprised 41 males and 26 females (five did not indicate their sex) aged between 18 and $45(M=21.78 ; S D=5.22)$.

\subsubsection{Procedure and measures}

Students were asked to take part in the present investigation at the beginning of a lecture and were told that they would be responding to two separate and unrelated studies. The first study was presented to the participants as if it aimed to validate new measures. This was our pretext to measure their BJW and the identification with other students of the same university. The second study was introduced as an investigation of how people form first impressions of others based on limited information and included the story about an innocent victim. Then, participants responded to measures of victim innocence and evaluation. All responses were made on 7-point scales with endpoints ranging from 1 "strongly disagree" to 7 "strongly agree". After completing the questionnaire booklet, participants were thanked and fully debriefed. This included stressing that the victimization situation presented was fictional, and giving information about victim derogation. The contact of the main researcher was also provided in case participants had further questions.

3.1.2.1. Belief in a just world. BJW was assessed with the Portuguese translation of the six-item General Belief in a Just World Scale by Dalbert, Montada and Schmitt (1987; e.g. "I think basically the world is a just place").

In order to avoid priming participants with the topic of justice, we intertwined the previous items with 16 unrelated items. (e.g., "I prefer cinema to theatre"). Only the scores from the BJW items were averaged showing adequate internal consistency $(\alpha=.64)$. Higher scores indicated stronger endorsement of the BJW.

3.1.2.2. Group identification. We used the 14 items of ingroup identification scale adapted from Leach et al.'s (2008) (e.g. "I am glad to be a student of my university", $\alpha=.91$ ). We considered the measure as unidimensional because the scale was translated into Portuguese and the number of participants was not enough to confirm the multidimensional structure of the scale in this sample.

3.1.2.3. Victimization situation. Participants read a story about another student (X) from the same university (ingroup) who was a victim of a car accident on a busy street across the university. Participants read:

"Question: Can you tell us what happened? X's answer: Yes, I had finished my lectures on a Tuesday and was going home. It had been a typical day until the moment I left university. When I tried to cross the avenue [the name of the street across the university was indicated], I was hit by a car that was going really fast. The driver didn't stop at the red traffic light and when s/he saw me, s/he tried to stop but it was already too late. This was my last memory of the accident. After leaving the hospital, the police told me that the driver had too much alcohol in his/her blood.

Question: What is the impact of this accident on your life? X's answer: I never imagined that it could happen to me. Now I can't move from my neck downwards. I can't move my legs and arms and I need to use a wheelchair. It is going to be like this for years and years to come...
3.1.2.4. Innocence of the victim. The perception of victim innocence was checked with two items: " $X$ is responsible for his/her situation" and "X could have avoided his/her situation". A higher score indicated a stronger belief in the victim's innocence $(r=.57$, $p<.001)$.

3.1.2.5. Victim evaluation. The victim was evaluated with seven traits: bad, self-centered, spineless, hostile, arrogant, competitive (all reverse coded), helpful, and intelligent ( $\alpha=.82$ ). After reversing the respective items, a higher score indicated a more positive evaluation of the victim.

\subsection{Results}

\subsubsection{Preliminary analysis}

Participants' sex and age were not correlated with the key variables of the study and hence were not included in further analyses. Most participants assessed the victim as being innocent $(M=2.51$, $S D=1.33$ ). A $t$-test confirmed that the mean was significantly lower than the midpoint of the scale, $t(71)=-9.56, p<.001$.

\subsubsection{Victim evaluation}

We tested whether group identification moderated the relationship between BJW and the evaluation of the victim. We conducted a regression where we introduced participants' BJW, group identification, and the product between the two as predictors. All variables were centered before the analysis (Aiken \& West, 1991). Victim evaluation was introduced as the outcome variable.

As expected neither identification nor BJW alone predicted evaluation of the victim. There was, however, an interaction effect of the two variables, $B=-.36, t(68)=3.17, p=.002$. As can be seen in Fig. 1, simple slope analysis showed, as predicted, that for high believers in a just world BJW (i.e., 1 SD above the mean), identification was negatively associated with evaluations of the victim,

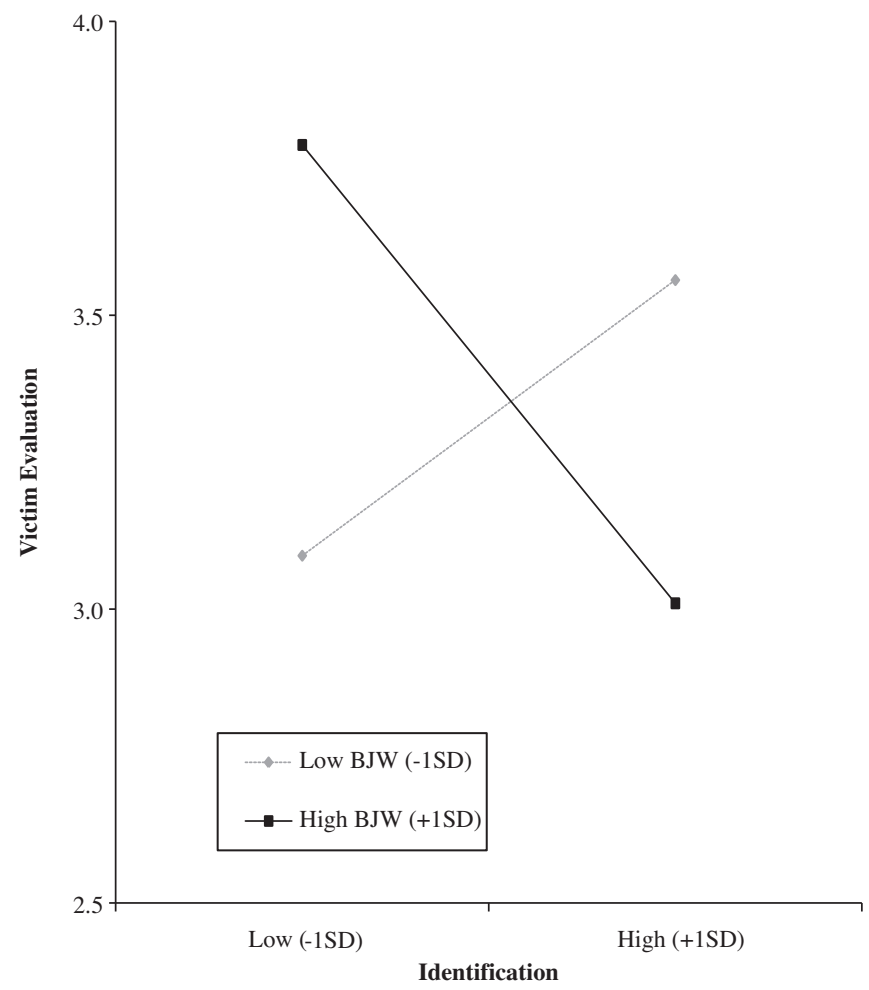

Fig. 1. Study 1: Victim evaluation as a function of BJW and identification. Means are plotted at high ( +1 SD) and low ( -1 SD) levels of BJW and ingroup identification. 
$B=-.36, t(68)=2.45, p=.017$. For those who were less inclined to believe in a just world (i.e., 1 SD below the mean), identification was not significantly associated with evaluations of the victim, $B=.21, t(68)=1.44, p=.155$.

\subsection{Discussion}

This study intended to evaluate the association between BJW and social identification in the derogation of an ingroup innocent victim. We predicted and found an interaction between BJW and social identification: for high believers in a just world there was an association between identification of an ingroup victim and victim derogation. This means that higher believers in a just world that were more identified with the (innocent) victim's group (the university) derogated him/her more than higher believers in a just world that were less identified with the same group. Among low believers in a just world, derogation of the victim remained constant across different levels of social identification.

\section{Study 2}

In this study we aim to test if there is an interaction between the observers' explicit endorsement of the BJW and group identification on psychological distancing from a victim who shares a common identity with the observer.

\subsection{Methods}

\subsubsection{Participants and design}

Ninety-four university female students took part in this study. Their age ranged from 18 to 49 years old $(M=23, S D=5.88)$. Participation was voluntary. All participants were randomly assigned to one of the experimental conditions: group salience (group identification salient vs. non-salient).

\subsubsection{Procedure}

The study was presented to participants as in Study 1. Participants were asked to read a brief text with an interview of a woman who was infected with HIV. Participants read:

Question: Do you know why you were infected with HIV? Answer of X: Yes, I was contaminated after a blood transfusion. I had a medical problem, went to the hospital and had a blood transfusion that later was found to be contaminated with HIV. Question: Could you have done something to avoid it? Answer of X: No, I was feeling very weak lying down on a hospital bed and the doctor that was taking care of me decided to make the blood transfusion. No one could suspect that the blood was infected. Question: And what is the impact of this situation in your life? Answer of X: Every day I have to take lots of medication with strong side-effects - in most days I just want to lie down because of all the dizziness and I know that this will last for years and years. .

This second study also included our manipulation (group salience: salient vs. non-salient) and served to assess the victim's innocence and identification with other females. After completing all questions, participants were fully debriefed as in Study 1 and thanked for their participation.

\subsection{Measures}

\subsubsection{Belief in a just world}

BJW was assessed using Study 1's measure $(\alpha=.62)$.

\subsubsection{Manipulation of group identification}

Social identification was manipulated through group salience membership. For the group salience condition (intended to induce high identification) we informed at the beginning of the questionnaire's second study that the goal was to examine how women form first impressions based on limited information. Based on a manipulation of Smith, Spears, and Oyen (1994) we also asked all participants to write their participant number on top of each page where they could read "woman number:

". For the non-group salience condition (intended to induce low identification) we merely stated that the aim of the study was to understand how people form first impressions based on limited information. They also had to write their participant number on top of each page where they read "participant number:__. The "participant/woman numbers" were randomly attributed and were unknown to the experimenter so that the participants were assured that their responses would remain anonymous.

\subsubsection{Innocence of the victim}

The victim innocence was measured with three items (e.g., " $\mathrm{X}$ could have avoided her accident", $\alpha=.60$ ).

\subsubsection{Group identification}

We measured the extent to which participants were identified with being a woman by adapting four items from Leach et al's (2008) tapping into feelings of satisfaction with group (e.g. "I am glad to be a woman", $\alpha=.75$ ).

Finally, we asked their gender and age.

\subsection{Results}

\subsubsection{Preliminary analysis}

Participants' age was not correlated with the key variables of the study and hence was not included in further analyses. Most participants assessed the victim as being innocent $(M=2.09$, $S D=1.24)$. A $t$-test confirmed that the mean was significantly lower than the midpoint of the scale, $t(93)=-15.01, p<.001$.

\subsubsection{Testing the moderation model}

We tested whether the group salience condition moderates the relationship between BJW and identification with other women. We conducted a regression where we introduced participants' BJW, group salience condition (coded "-1" non-salient and "1" salient), and the product between the two as predictors. All variables were centered before the analysis (Aiken \& West, 1991). Identification was introduced as the outcome variable.

Again neither BJW nor the group salience condition alone predicted identification, $B=-.05, t(86)=0.42, p=.677$ and $B=-.02$, $t(86)=0.22, p=.825$. There was, however, an interaction effect of the two variables, $B=-.23, t(86)=2.16, p=.034$. As can be seen in Fig. 2, simple slope analysis showed, as predicted, that for participants in the non-salient condition, BJW was not associated with ingroup identification, $B=.13, t(86)=0.93, p=.356$. For those who were in the group salience condition, believing in a just world was associated with low ingroup identification, $B=-.32$, $t(86)=2.03, p=.045$.

\subsection{Discussion}

This study intended to evaluate the impact of the interplay between BJW and group membership on psychological distancing from an ingroup innocent victim. We predicted and found an interaction effect between BJW and social identification. When group salience was activated, and therefore social identification was higher, believing in a just world was associated with low ingroup 


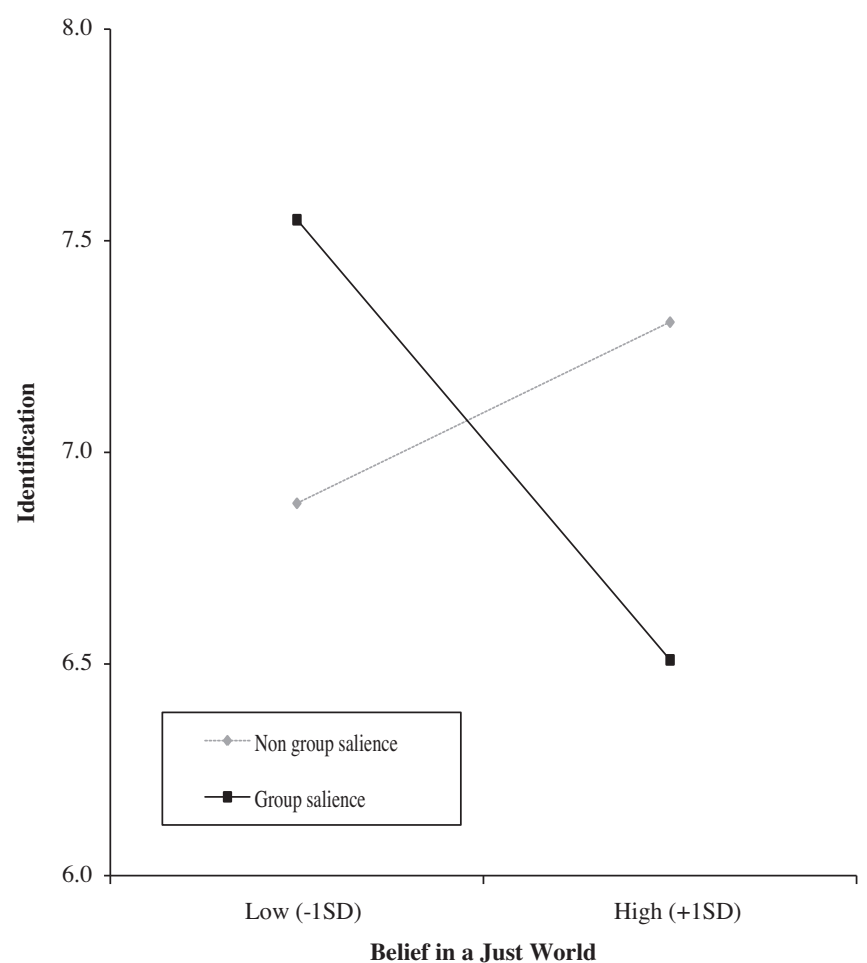

Fig. 2. Study 2: Ingroup identification as a function of group salience and BJW. Means are plotted at high (+1 SD) and low ( -1 SD) BJW.

identification (i.e., satisfaction with a being a woman). However, no effects were found when group salience was not activated.

This means that higher believers in a just world under conditions of higher ingroup salience identify less with the group shared with the innocent victim than higher believers in a just world when the common identity with the victim is not salient. Among low believers in a just world, identification with the group of the victim remained constant whether this group membership was activated or not.

\section{General discussion}

The results from both studies supported the hypothesis that there would be more victim derogation (Study 1 ) and less identification with the group shared with the victim (Study 2) when the threat to BJW was highest - that is, when the observers strongly believe in a just world and more strongly identify with the group to which the innocent victim belongs.

Study 1 extends the findings of Aguiar et al. (2008) that an ingroup innocent victim is more threatening to the observers' BJW in two ways. Firstly, it shows that derogation may be found in an explicit measure and not only at an implicit level. Secondly, it shows that the strength of identification with a group can be associated with more derogation of a victim of that group, and it is not merely an effect of categorization. When the victim is an ingroup member higher identification increases the perception of interchangeability between observers and the victim. Consequently, high believers in a just world who are also highly identified with their ingroup are especially motivated to derogate the victim in order to restore their threatened BJW.

In Study 2 the social identification with the group was manipulated through group salience such that identification would be stronger when the common group with the victim was salient compared to when that shared membership was not salient. We found that high believers in a just world reported lower identifica- tion with women than low believers (only) when their identity as women had been made salient. This is a novel finding as previous research had never found an interaction between measured BJW and group membership on psychological distancing. This interaction effect shows the importance of identification and explains to a certain extent why previous work failed to find results linking BJW and psychological distancing.

Therefore, as already shown in other domains, such as other group phenomena (Eidelman \& Biernat, 2003), although target devaluation and group disidentification appear different on the surface, they both may serve the common end of distance augmentation. An important development of this study would be to manipulate the availability of these two possible routes to escape threat to BJW and ascertain whether they are mutually exclusive or they operate simultaneously and additively as it has been done with other group phenomena (for a review, see Eidelman \& Biernat, 2003).

We also think that the measure used in Study 1 for evaluating the victim deserves further investigation. Our measure comprised eight items of which six were negative and two were positive, one related to competence and seven related to warmth (Fiske, Cuddy, Glick, \& Xu, 2002). However, previous research has not made a distinction between these dimensions and one suggestion would be to examine the effects of derogation considering the competence and warmth distinction (Fiske et al., 2002) and the positive-negative asymmetry (e.g. Gaertner \& McLaughlin, 1983).

Future studies should try to replicate these results with different samples, different situations of victimization, different social identities and different measures of identification with the victim. In fact, in Study 2 we found a lower identification with the victim with a measure of satisfaction. Future studies should also try to replicate these results by experimentally manipulating BJW or/ and identification, which would allow one to ascertain the causal direction of the effect. Another possibility would be to assess the increased perception of vulnerability as a possible mediating mechanism of these processes.

Overall, we believe that our study is an important step ahead given that it explores theoretically and empirically for the first time the importance of social identification as a factor that increases threat to BJW but may also be affected by threat to BJW.

\section{Acknowledgement}

This research was supported by a grant from Fundação para a Ciência e Tecnologia (PTDC/PSI-PSO/098110/2008).

\section{References}

Aguiar, P., Vala, J., Correia, I., \& Pereira, C. (2008). Justice in our world and in other's world: Belief in a just world and reactions to victims. Social Justice Research, 21, 50-68.

Aiken, L. S., \& West, S. G. (1991). Multiple regression: Testing and interpreting interactions. Newbury Park, CA: Sage.

Correia, I., \& Vala, J. (2003). When will a victim be secondarily victimized? The effect of observer's belief in a just world, victim's innocence and persistence of suffering. Social Justice Research, 16, 379-400.

Correia, I., Vala, J., \& Aguiar, P. (2007). Victim's innocence, social categorization and the threat to the belief in a just world. Journal of Experimental Social Psychology, 43, 31-38.

Dalbert, C., Montada, L., \& Schmitt, M. (1987). Glaube an die gerechte Welt als Motiv: Validierung zweier Skalen. Psychologische Beitrage, 29, 596-615.

Drout, C. E., \& Gaertner, S. L. (1994). Gender differences in reactions to female victims. Social Behavior and Personality, 22, 267-278.

Eidelman, S., \& Biernat, M. (2003). Derogating black sheep: Individual or group protection? Journal of Experimental Social Psychology, 39, 602-609.

Fiske, S. T., Cuddy, A. J. C., Glick, P., \& Xu, J. (2002). A model of (often mixed) stereotype content: Competence and warmth respectively follow from perceived status and competition. Journal of Personality and Social Psychology, $82,878-902$. 
Gaertner, S. L., \& McLaughlin, J. P. (1983). Racial stereotypes: Associations and ascriptions of positive and negative characteristics. Social Psychology Quarterly, $46,23-30$.

Hafer, C. L. (2000a). Do innocent victims threaten the belief in a just world? Evidence from a modified Stroop task. Journal of Personality and Social Psychology, 79, 165-173.

Hafer, C. L. (2000b). Investment in long-term goals and commitment to just means drive the need to believe in a just world. Personality and Social Psychology Bulletin, 26, 1059-1073.

Hafer, C. L., \& Bègue, L. (2005). Experimental research on just-world theory: Problems, developments, and future challenges. Psychological Bulletin, 131, 128-167.

Jackson, J. W. (2002). Intergroup attitudes as a function of different dimensions of group identification and perceived intergroup conflict. Self and Identity, 1, 11-33.

Leach, C. W., van Zomeren, M., Zebel, S., Vliek, M., Pennekamp, S. F., Doosje, B., et al. (2008). Group-level self-definition and self-investment: A hierarchical (multicomponent) model of in-group identification. Journal of Personality and Social Psychology, 95, 144-165.
Lerner, M. J. (1980). The belief in a just world: A fundamental delusion. New York: Plenum Press.

Lerner, M. J., \& Miller, D. T. (1978). Just world research and the attribution process: Looking back and ahead. Psychological Bulletin, 85, 1030-1051.

Novak, D. W., \& Lerner, M. J. (1968). Rejection as a consequence of perceived similarity. Journal of Personality and Social Psychology, 9, 147-152.

Smith, H. J., Spears, R., \& Oyen, M. (1994). "People like us:” The influence of personal deprivation and group membership salience on justice evaluations. Journal of Experimental Social Psychology, 30, 277-299.

Tajfel, H. (1978). Differentiation between social groups. London: Academic Press.

Tajfel, H., \& Turner, J. C. (1979). An integrative theory of intergroup conflict. In W. G. Austin \& S. Worchel (Eds.), The social psychology of intergroup relations. Monterey, CA: Brooks-Cole.

Turner, J. C. (1999). Some current issues in research on social identity and selfcategorization theory. In N. Ellemers, R. Spears, \& B. Doosje (Eds.), Social identity context, commitment, content (pp. 6-34). Oxford: Blackwell Publishers.

Turner, J. C., Hogg, M. A., Oakes, P. J., Reicher, S. D., \& Wetherell, M. S. (1987) Rediscovering the social group: A self-categorization theory. Oxford, England: Blackwell. 